\title{
Research on training mode of computer network based on competency
}

\author{
Xiaozhong Chen ${ }^{a}$, Zhijian Mao ${ }^{\mathrm{b}}$
}

School of information, Changzhou Vocational Institute of Engneering, Changzhou 213164, China.

a chenxiaozhonghh@163.com, ${ }^{\mathrm{b}}$ zjmao@email.czie.net

Keywords: Post competency, computer network major, curriculum reform.

\begin{abstract}
Job competency model, as an organization can enhance the core competitiveness of the talent management model, has been widely recognized by many enterprises and institutions. This article will post competency theory into the computer network of professional personnel training and curriculum reform, refining Competency elements to build a computer network Competency typical model of computer network specialty typical job capacity and systematic approach to quality vocational training for enhance students' professional core competencies, improve the quality of personnel training reference.
\end{abstract}

\section{Introduction}

Post competency refers to a specific position in the successful completion of the job requirements of the individual should have a comprehensive feature elements, including knowledge, skills, abilities, qualities, actions, attitudes, responsibilities and methods; competency model has been widely used many well-known enterprise management in order to enhance executive power and core competitiveness [1]. As training skilled personnel colleges, I believe that should be typical of the competence to introduce training and curriculum construction talents; summarized the competence of enterprise characteristic factors, refining, summed up the knowledge, skills, qualities, responsibilities and attitudes five areas; cultivate high-quality computer network professionals, Vocational Training and achieve seamless connection between business job employment goals.

\section{Situation and problems of computer network learning}

In the "Internet +" has become the new norm today, the rapid development of computer network technology, new technologies, new applications emerging, driving many industries, upgrading of enterprises. Faced with new challenges, many domestic vocational institutions have made a lot of reform and research personnel training and curriculum system construction. Proposed cooperation with enterprises, internships, courses replacement and other reference methods, and have achieved varying degrees of success. In recent years, the overall quality and capacity of the computer network of a general increase in graduates; as a key indicator of personnel training vocational, corporate human talent evaluation department satisfaction also increased year by year. However, the construction of professional computer network, there are still the following problems.

The competence is not strong. With respect to the colleges students academic ability, vocational colleges more emphasis on practical application of culture. Many domestic colleges Vocational Training programs, theoretical and practical course almost half and half, in order to enhance students practical hands-on skills. However, to isolate the theoretical courses and practical courses, the lack of organic integration of the two should be such that the student will be difficult theory to guide practice, difficult to use practice to test theory; cause "theory does not understand", "Practice does not understand", etc. situation. Furthermore, in terms of the ability to post responsibility, communication, teamwork and so lacking. Resulting in their actual positions graduates can not be competent, less than the expected value of the business requirements [2]. 
Training targeting not allowed. Applications covering industries of computer network expertise, field, jobs involving multiple groups. Many computer network of professional colleges and universities will be website development, network maintenance, network engineering, security, product sales, etc. As a graduate of the goal posts, which set up the website development, network construction and network server system deployment, network security, cabling, etc. a series of professional courses. Students learn the content is "wide", look what will be, but in fact everything so that we can, not "special." Thus, a graduate can not cope with any expected goal posts often the case, because the students lack the core competitiveness of the corresponding positions.

Curriculum design and professional combination is not tight. Computer network system is usually caused by multi-device, multi-service, multi-application integration system configuration. It requires students to build network in this integrated environment, optimization and management. Many courses are of a part of the local learning and training, such as server deployment, network construction, integrated wiring, difficult skill points more organic integration course, difficult for students to have a "net" feeling. Even open network systems integration and other integrated programs, often due to limited practice environment and equipment sets of copy number, difficult to implement, the actual effect is minimal.

School-enterprise cooperation is not deep enough. Because of the need to introduce the practice facilities, businesses and vocational colleges to some extent, often forming a partnership to create a practice base outside school, as well as "Colonel factory" in the enterprise, "Factory in Schools" model. On the one hand, since the target enterprises and vocational colleges is different because the company's goal is to maximize the benefits, in school-enterprise cooperation, enterprises need to pay a lot of resources to assist students, and our corporate social responsibility generally not high; the other hand, , graduate school culture can not be directly used for business, they can not quickly qualified for a particular job. These have led to cooperation between schools and enterprises were unable to penetrate.

Therefore, higher vocational colleges should be based on realistic and social development, industry-oriented, with a typical career objectives and job requirements, design and curriculum reform in all aspects, such as objectives, content and organization, implementation and evaluation, focus on training the students' practical ability and professional capability.

\section{Competency analysis and model construction of target position}

Colleges and vocational training to adapt to the social development of the industry can be advanced applied talents, industries and enterprises must be based on a typical docking to seek the goal posts will train qualified enterprise computer network talents as the culture focus.

3.1 Job analysis and goal posts Location

Through extensive research and business visits of professional depth feasibility studies, to determine the computer network positioning technology Professional Training: "The network can be built, understand the network, the network will use the" adaptation "Internet + " new normal application of high-quality skilled personnel. Computer network technology for professional personnel training orientation, according to the needs of the enterprise network construction and management, computer networking graduates Higher positioning network engineers and network administrators two levels of jobs. Network engineers, network integrators (pre-sale) planning and implementation of the post, the network administrator for the campus network, enterprise network's daily operation and maintenance and management positions.

\subsection{Position and competency analysis}

The ability to post more than just qualifications skills, also includes professional competence, methods, capacity, social capacity of the competence. According to the statistical results of the questionnaire to a large number of corporate human resources department of the two goal posts and jobs in the field of features extracted. Network engineer jobs areas of work include: research and customer needs analysis, network planning and design, project and construction management, project acceptance and delivery, engineering documents prepared and submitted the like; and the network 
administrator areas of work include: research and summarizes the needs of users, project budget, network planning, project tracking and inspection, maintenance, and other network transformation and upgrading. Each field has its own typical work tasks, combined with professional qualification criteria, complete the required skills and professional qualities, and to determine the competency of the characteristic elements of the model response.

\subsection{Construction of post competency model}

To realize the "combination working with learning capability based" training mode of teaching quality, competency-based elements of the two goal posts in the areas of work, the author of the Yangtze River Delta area network systems integrator $50 \mathrm{HR}$ (30), and enterprise networks information Center (20) supervisor questionnaires from 30 competency elements of the research, the extract 10 major wins characteristic elements, and in accordance with the priority order, the goal of building the competence simplified model, as shown in table 2 shown, communication, execution and learning ability is located in the most important position, the most valued corporate job, which is the traditional expertise of the training, a large gap.

Table 1 Competency model of target position

\begin{tabular}{cll}
\hline Priority & \multicolumn{1}{c}{ Feature } & \multicolumn{1}{c}{ Explation } \\
\hline 1 & communication & $\begin{array}{l}\text { Grasp the key points and the other expression, fluent in expressing their } \\
\text { ideas and thoughts. } \\
\text { To grasp and understand the relations of power. } \\
\text { To keep abreast of industry development, technology, can quickly learn } \\
\text { new knowledge, and flexible use. }\end{array}$ \\
4 & $\begin{array}{l}\text { study } \\
\text { implement }\end{array}$ & $\begin{array}{l}\text { Actively cooperate with the work of others, can become a member of the } \\
\text { popular group. }\end{array}$ \\
5 & deamwork & $\begin{array}{l}\text { Good help and serve others, and strive to provide the best service to } \\
\text { customers. }\end{array}$ \\
6 & $\begin{array}{l}\text { flexibility } \\
\text { affinity } \\
\text { emotion control }\end{array}$ & $\begin{array}{l}\text { In different circumstances, different situations can actively change. } \\
\text { Ability to be kind, easy-going and easy to communicate with others. } \\
\text { In a variety of circumstances, to remain calm, to suppress negative } \\
\text { emotions and actions. }\end{array}$ \\
\hline
\end{tabular}

\section{Curriculum reform and Implementation}

4.1 Competence based curriculum system optimization

Competency for the table, re-optimize the backbone of professional courses to achieve docking Competency and Curriculum objectives, in training professional skills of students, while others focus on training Competency. Computer Network Curriculum System include: integrated wiring, network formation and maintenance, server system management and configuration, database technology, network security technology, network equipment and integration, project management, internship, focused attention to inter-course convergence, full It reflects the objective job requirements.

4.2 Reflecting organizational competency

How effective teaching, focusing on curriculum system implementation. Since 2007, the project-based teaching model to explore in our hospital, and the hospital to promote professional and achieved good results. The project teaching relatively close to the actual computer network engineering, so in many courses, such as network equipment and systems integration, program design is no longer with the knowledge, skill point as the center for the design, construction and the use of the process of the project, role-division team set up in the form of the project team organized student. Use of the program submission, the real process of project reporting, project display, bidding, etc., based on the assessment of project engineering specifications, providing all-round student of the competence, especially in communication and teamwork. The teaching process, requiring specialized teachers themselves should have a strong job competency, and can play the role of related positions, curriculum organization, communication, evaluation. 
4.3 Optimization training environment

Vocational Students Practical Training Course directly affect the competence training. As part of the network equipment and integration, often because of devices, applications, and services of a large number, the network needs to reach a certain size; traditional laboratory can not provide the whole class learning together training environment. Simulation environment can be an important way to solve these problems, teachers need professional design and development resources projects based on simulation environment, based on the project specifications and process engineering design subprojects, tasks, and test platform designed to facilitate independent learning.

In addition, the company's internship is another important way to cultivate competence. However, due to the problem of computer network professional nature and quantity of jobs, generally, a class of students is difficult to carry out one or several joint venture internships. Thus, on the one hand, students can be divided into several batches to cooperative enterprise internships; on the other hand, it may invite the competent corporate job or project manager to school, according to the real process of training students in the class project.

\section{Summary}

The competence is an important guiding computer network professional training in higher vocational colleges. Currently, the competence of graduates is not strong mainly due to the school's training mode and employment needs of enterprises there is a big gap. Although many colleges and universities are actively promoting cooperation with enterprises, however, the lack of substance and depth of cooperation, it is often difficult to solve the problem of the competence of graduates. I believe that computer networks majors in higher vocational colleges, we should start to build the competence model for Competency requirements, optimizing curriculum system design, a clear ability training curriculum, deepen the reform of teaching methods courses, students focusing on competence rather than just job expertise. With the promotion of national policy in the future development, we will be school-enterprise cooperation to develop in depth, distance between schools and businesses will be further reduced, employment core competitiveness of the graduates will be increased gradually. Thus, the competency model of professional vocational guidance, curriculum design will have a larger space for development.

\section{Acknowledgements}

This study was financially supported by the Foundation of Modern Educational Technology of Jiangsu Province [45382] and the Foundation of Changzhou Vocational Institute of Engineering [ZY6105016].

\section{References}

[1]. Mcclelland D C.Identifying competencies with Behavioral Event Interviews[J]. Pshcho logical Scienece, 1993(9):311-339.

[2]. Fan Lande, Huang Fang. Higher vocational education curriculum reform under the demand of professional competence [J]. Education Review, 2013 (3): 42-44. 